\title{
COPD in Taiwan: a National Epidemiology Survey
}

This article was published in the following Dove Press journal:

International Journal of COPD

II November 2015

Number of times this article has been viewed

\section{Shih-Lung Cheng, ${ }^{1,2}$ Ming- Cheng Chan, ${ }^{3}$ Chin-Chou Wang, ${ }^{4}$ Ching-Hsiung Lin, ${ }^{5}$ Hao-Chien Wang, ${ }^{6}$ Jeng-Yuan Hsu, ${ }^{3}$ Liang-Wen Hang, ${ }^{7,8}$ Chee-Jen Chang, ${ }^{9}$ Diahn-Warng Perng, ${ }^{10, *}$ Chong-Jen Yu ${ }^{6, *}$}

\section{On behalf of the Taiwan} COPD Consortium

'Department of Internal Medicine, Far Eastern Memorial Hospital, New Taipei City, ${ }^{2}$ Department of Chemical Engineering and Materials Science, Yuan Ze University, Chung-Li City, Taoyuan County, ${ }^{3}$ Department of Internal Medicine, Taichung Veterans General Hospital, Taichung, ${ }^{4}$ Division of Pulmonary and Critical Care Medicine, Kaohsiung Chang Gung Memorial Hospital, Kaohsiung, ${ }^{5}$ Division of Chest Medicine, Changhua Christian Hospital, Changhua City, Changhua County, ${ }^{6}$ Department of Internal Medicine, National Taiwan University Hospital, Taipei, 'Department of Pulmonary and Critical Care Medicine, Sleep Medicine Center, China Medical University Hospital, ${ }^{8}$ Department of Respiratory Therapy, College of Health Care, China Medical University, Taichung, 'Biostatistical Center for Clinical Research, Chang Gung Memorial Hospital, Linkou Branch, Guishan Township, Taoyuan County, ${ }^{10}$ Department of Chest Medicine, Taipei Veterans General Hospital, Taipei, Taiwan, Republic of China

*These authors contributed equally to this work

Correspondence: Chong-Jen Yu Department of Internal Medicine, National Taiwan University Hospital, 7 Chung-Shan South Road, Taipei 100, Taiwan, Republic of China

Tel +886223123456 ext 2905

Fax +886223582867

Email jefferycjyu@ntu.edu.tw

Diahn-Warng Perng

Department of Chest Medicine, Taipei Veterans General Hospital, 20I, Section 2, Shipai Road, Taipei I I2, Taiwan, Republic of China

Tel +8862 287। 212l ext 2078

Email dwperng@vghtpe.gov.tw
Objectives: To determine the prevalence of COPD in Taiwan and to document the disease characteristics and associated risk factors.

Methods: We conducted a random cross-sectional national survey of adults older than 40 years in Taiwan. Respiratory health screening questions identified subjects with diagnosed COPD or whose reported symptoms also fulfilled an epidemiological case definition; these were eligible to complete the survey, which also included indices of symptom severity and disability and questions on comorbidities, medical treatments, smoking habits, and occupations potentially harmful to respiratory health. Subjects with diagnosed COPD were subdivided by smoking status. Subjects who fulfilled the case definition of COPD and smoked were designated as "possible COPD". Participants who did not fit the case definition of COPD were asked only about their personal circumstances and smoking habits. Data from these groups were analyzed and compared.

Results: Of the 6,600 participants who completed the survey, 404 (6.1\%) fulfilled the epidemiological case definition of COPD: 137 with diagnosed COPD and 267 possible COPD. The most common comorbidities of COPD were hypertension or cardiovascular diseases $(36.1 \%)$. Subjects with definite COPD had significantly higher COPD Assessment Test scores than the possible COPD group (14.6 \pm 8.32 vs $12.6 \pm 6.49, P=0.01)$ and significantly more comorbid illnesses $(P=0.01)$. The main risk factors contributing to health care utilization in each COPD cohort were higher COPD Assessment Test scores (odds ratio [OR] 1.15, 95\% confidence interval [CI] 1.04-1.26), higher modified Medical Research Council Breathlessness Scale scores (OR 1.97, 95\% CI 1.11-3.51), and having more than one comorbidity (OR 5.19, 95\% CI 1.05-25.61).

Conclusion: With estimated prevalence of $6.1 \%$ in the general population, COPD in Taiwan has been underdiagnosed. Symptoms and comorbidities were independent risk factors for health care utilization in subjects with definite or possible COPD. There is an urgent need to raise awareness of the importance of early evaluation and prompt treatment for subjects with chronic airway symptoms.

Keywords: Asia, COPD, epidemiology, health care utilization, risk factors

\section{Introduction}

COPD is a leading and increasingly important cause of morbidity and mortality worldwide that is projected to become the third leading cause of death by $2020 .{ }^{1,2}$ COPD also incurs substantial psychological and social burdens as a result of cumulative exposure to risk factors and population aging, as well as extra direct and indirect medical expenditures that impose a substantial economic burden. ${ }^{3,4}$ As a major public health problem, precise and informative epidemiological data about COPD are needed; however, reported prevalence estimates vary widely due to differing definitions and methodologies. ${ }^{3}$

The Asia-Pacific region bears the highest burden of COPD in terms of deaths, years spent living with disability, and years of life lost; however, the prevalence 
varies between countries in this region. ${ }^{5}$ In a large-scale spirometry-based survey of COPD in the People's Republic of China, $35.3 \%$ of those who fulfilled the diagnostic criteria for COPD were asymptomatic and only $35.1 \%$ reported lifetime diagnosis of bronchitis, emphysema, or other COPD. ${ }^{6}$ The average annual prevalence of COPD in Taiwan based on national health insurance medical reimbursement claims from 1996 to 2002 was $\sim 2.5 \%$. $^{7}$ An earlier analysis of national mortality and population data from Taiwan showed that the mortality rate for COPD rose gradually during the $1990 \mathrm{~s}^{8}{ }^{8}$ However, COPD mortality is probably underestimated, as COPD is known to be underreported on death certificates. $^{9}$ Furthermore, there is considerable uncertainty concerning the accuracy of these data because the diagnosis was not standardized and the definition and management of COPD have evolved over the past 2 decades.

Although COPD is treatable and preventable, it is often underrecognized and underdiagnosed. Tobacco smoking is the most common risk factor for COPD, especially in the developed world; however, emerging evidence suggests that other risk factors are also important, especially in developing nations. These additional risk factors include indoor and outdoor air pollution, domestic use of biomass fuels, occupational exposure to dust and fumes, chronic asthma, and previous tuberculosis infection. ${ }^{6,10}$

For these reasons, updated epidemiological data are required to inform the implementation of effective public health strategies intended to better prevent and manage COPD. To this end, we conducted a random survey of adults older than 40 years in Taiwan to determine the national prevalence of COPD and to document the disease characteristics and associated risk factors.

\section{Methods}

\section{Research protocol}

We used a computer-assisted telephone interviewing system to conduct a random population-based cross-sectional survey of adults aged 40 years and older, resident in cities/counties/ regions throughout Taiwan, Republic of China. The systematic sampling technique used national telephone number records. To constitute a representative national sample, the latest population statistics published by the Taiwan (Republic of China) Ministry of the Interior were used to restrict demographic data to quotas for age group, sex, and area/county/city of residence. Trained interviewers made calls from January 19 to May 8, 2013, to establish potential household contacts. Participation was voluntary, and contacted individuals gave verbal informed consent before the interview and were free to withdraw at any stage. To protect anonymity and confidentiality, all identifying data were delinked before analysis. This protocol was exempt from ethics approval because the subjects volunteered at no cost to themselves and the results had no medical implications for individual participants.

Successful initial contacts were filtered against exclusion criteria: age $<40$ years; exceed demographic quota(s); prior interview/meeting relating to health care, market research, or advertising; occupation of any domicile resident in advertising/market research/news media/public relations; or production/distribution/retail of medical or health care products.

\section{Respiratory health questionnaire}

Eligible contacts were asked five screening questions about COPD and respiratory symptoms to identify those with either diagnosed COPD or related respiratory symptoms (breathlessness, ongoing cough, cough with sputum, wheezing, and chest tightness) of $>3$ months duration that also fulfill an epidemiological case definition of COPD. These COPD cohorts were invited to complete the rest of the survey in full. In addition to eliciting basic information about age, marital status, education level, specific occupations potentially harmful to respiratory health, leisure activities, and smoking behavior, the survey form included a modified Medical Research Council Breathlessness Scale (mMRC), ${ }^{11}$ COPD Assessment Test (CAT), ${ }^{12}$ and questions about comorbid diseases (hypertension or cardiovascular disease, diabetes, stroke, cancer, and tuberculosis), medical treatments, and health care utilization. Participants without diagnosed COPD or symptoms consistent with the case definition were asked only selected questions to elicit basic information about their personal circumstances and smoking behaviors. Subjects from the COPD cohorts were divided into three groups. Those who reported having COPD diagnosed by a clinical specialist were designated as "definite COPD" and subdivided according to their smoking status (ever, current, and never). The third group was designated "possible COPD" by virtue of having respiratory symptoms that fulfill the epidemiologic case definition of COPD and also being ever-smokers. Data from each of these groups were analyzed and compared.

\section{Statistical analysis}

Standard statistical approaches were used to derive the frequencies, percentages, means, medians, and standard deviations of descriptive demographic variables (age, sex, smoking habits, 
mMRC, CAT score, and medical utilization). Proportions for dichotomous discrete outcomes were compared between groups using two-sample proportional, chi-square, Fisher's exact, and Kruskal-Wallis tests. Analysis of variance and the Wilcoxon rank sum test were used for continuous outcomes, and the Cochran-Mantel-Haenszel test for ordinal variables, such as different number of comorbidities between sexes. Multivariate logistic regression analysis was performed to ascertain and evaluate the risk factors contributing to the medical utilization of patients with COPD. Data were collected, entered, and managed using IBM SPSS Data Collection Version 6.0. Statistical analyses were performed using IBM SPSS Statistics Version 19. All tests were two sided. $P$-value of $<0.05$ was considered statistically significant.

\section{Results Epidemiology of COPD in the survey population}

The computer-assisted telephone interviewing system generated 195,212 telephone numbers that yielded 32,381 successful contacts, of whom 17,949 were eligible to participate in the survey. Of these, 6,600 subjects (response rate: $36.8 \%$ ) who successfully completed the interview constituted the screening population (Figure 1).

Among this nationwide sample of adults older than 40 years from the general population of Taiwan, 404 (6.1\%) fulfilled the epidemiological case definition of COPD: 137 (2.1\%) who reported having COPD diagnosed by a specialist - definite COPD and 267 (4.0\%) who fulfilled the epidemiologic

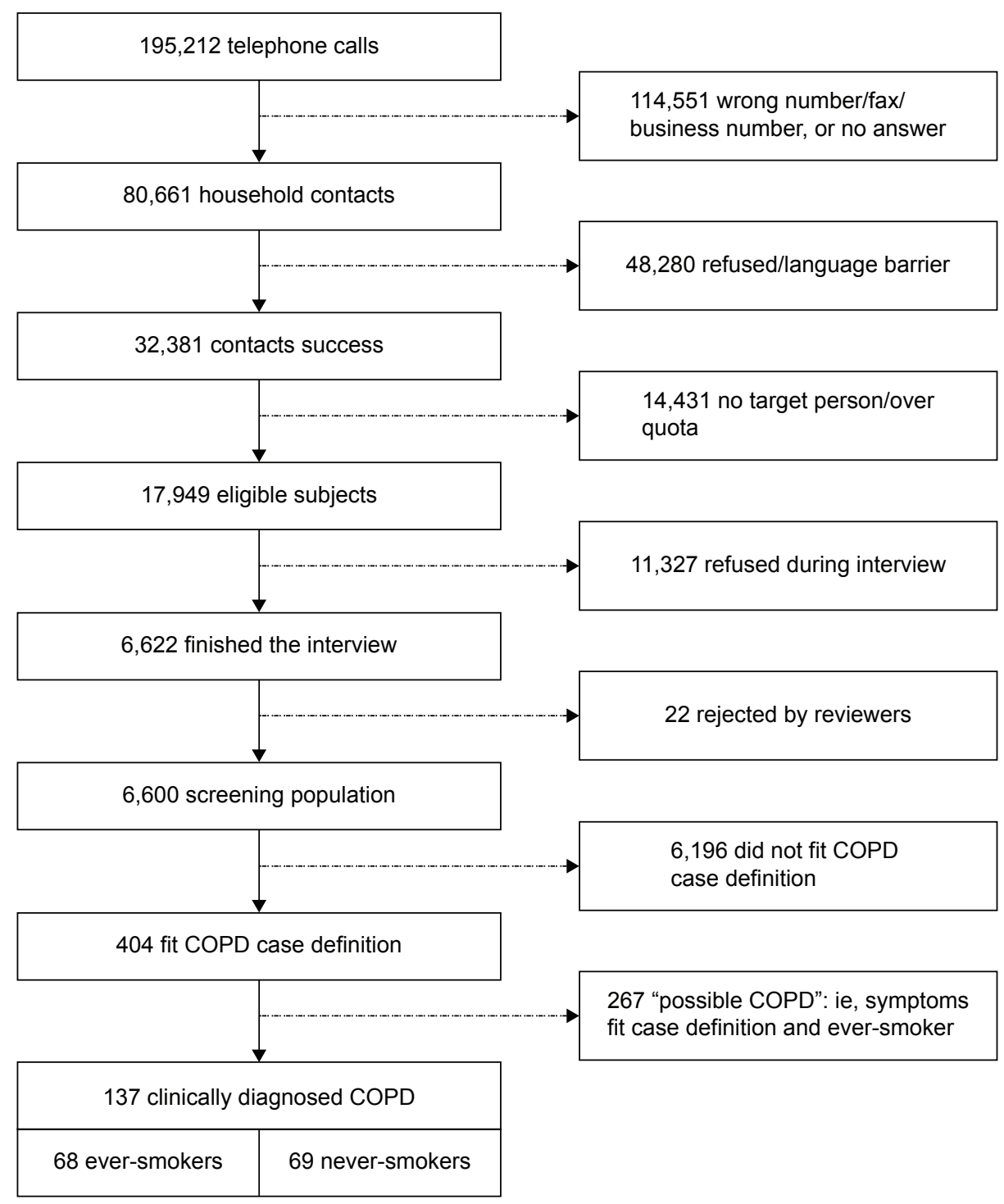

Figure I Subject flow for COPD cohorts. 
criteria by virtue of their symptoms and smoking history possible COPD. The remaining 6,196 subjects did not fit this epidemiologic case definition of COPD.

\section{Demographic characteristics and differences between COPD cohorts}

Among the combined COPD cohorts, males (78.9\%) and ever-smokers $(82.9 \%)$ predominated; approximately half (49.6\%) of the subjects with definite COPD were ever-smokers (Table 1), and there were proportionally more males in the combined COPD ever-smoker cohorts compared with COPD never-smokers $([60+237] / 404$ vs 22/404, $P<0.001)$. By extension, subjects with either definite or possible COPD who were male ever-smokers comprised a significantly greater proportion of the sampling population $(297 / 6,600=4.5 \%)$ than female ever-smokers $(38 / 6,600=0.6 \%)$, male never-smokers $(22 / 6,600=0.3 \%)$, or female never-smokers $(47 / 6,600=0.7 \%)$.

Subjects who reported being clinically diagnosed with COPD were significantly older than the group with possible COPD, and definite COPD was more prevalent among subjects who were aged 50 years or older $(11.1 \%-41.6 \%)$ than in those younger than 50 years $(6.3 \%-22.2 \%)$. Contrastingly, significantly higher proportions $(34.7 \%-56.4 \%)$ of those with possible COPD fell into the youngest age group (40-49 years) compared with those who were older $(P=0.002)$.

\section{Assessments of symptoms and comorbidities $\mathrm{mMRC}$ and CAT scores}

Cough with sputum (79\%), chest tightness (50\%), and persistent cough $(49.8 \%)$ were the most frequent respiratory symptoms in subjects with definite COPD. Although ever-smokers had numerically lower mMRC scores than never-smokers, this was not statistically significant $(0.7 \pm 0.9$ vs $1.0 \pm 0.9, P=0.16)$. However, subjects with definite COPD had significantly higher CAT scores compared with the possible COPD group (14.6 \pm 8.32 vs $12.6 \pm 6.49, P=0.01)$, as well as a significantly more comorbid illnesses $(P=0.01)$.

\section{COPD comorbidities}

Cardiovascular disease or hypertension was the most common type of comorbidity reported by subjects with either definite COPD or possible COPD (36.1\%), followed by diabetes mellitus $(11.9 \%)$, history of tuberculosis $(3.7 \%)$, cancer $(3.2 \%)$, and stroke $(1.7 \%)$.

Subjects with either definite or possible COPD who had two or more comorbidities reported worse shortness of breath and quality of life compared with those with one or no comorbidities (mMRC: $1.1 \pm 1.08$ vs $0.7 \pm 0.94$ and $0.7 \pm 0.69$, $P=0.022$; CAT score: $16.5 \pm 7.63$ vs $12.5 \pm 7.01$ and $13.3 \pm 7$, $P=0.002)$. The numbers of comorbid diseases increased with age (Table 2). Compared with subjects with one or no comorbidity, higher proportions of those with two or more comorbidities reported receiving regular treatment $(44.2 \%$ vs $23.5 \%$ and $16.7 \%, P<0.01)$ and being admitted to intensive care or intubated ( 0.8 vs 0.2 and $0.0, P=0.019$ ).

\section{Health care utilization and medical treatments COPD diagnosis}

Medical centers (39.7\%) and regional hospitals (37.1\%) were the predominant types of health care facility at which

Table I Screening population demographics and COPD status

\begin{tabular}{|c|c|c|c|c|c|c|c|c|}
\hline \multirow[t]{4}{*}{ Characteristic } & \multirow{4}{*}{$\begin{array}{l}\text { Non-COPD } \\
\text { population }\end{array}$} & \multicolumn{7}{|l|}{ COPD cohorts } \\
\hline & & \multicolumn{4}{|l|}{ Definite $^{a}$} & \multicolumn{3}{|l|}{ Possible $^{b}$} \\
\hline & & \multicolumn{4}{|l|}{ Smoking history } & \multicolumn{3}{|l|}{ Smoking history } \\
\hline & & Current $(n=36)$ & Former $(n=32)$ & Never $(n=69)$ & $P$-value & Current $(n=\mid 72)$ & Former $(n=95)$ & $P$-value \\
\hline Sex, n (\%) & & & & & $<0.00 \mathrm{I}^{\mathrm{c}}$ & & & $0.895^{d}$ \\
\hline Male & $2,905(46.9)$ & 33 (9।.7) & $27(84.4)$ & $22(31.9)$ & & $153(89.0)$ & $84(88.4)$ & \\
\hline Female & $3,219(53.1)$ & $3(8.3)$ & $5(15.6)$ & $47(68.1)$ & & $19(I I .0)$ & II (II.6) & \\
\hline \multicolumn{9}{|l|}{ Age (years) } \\
\hline Mean \pm SD & $56.6 \pm 11.7$ & $59.4 \pm 13.5$ & $64.3 \pm 12.4$ & $63.4 \pm 12.2$ & $0.217^{\mathrm{e}}$ & $51.1 \pm 9.9$ & $56.4 \pm 11.2$ & $<0.00 \mathrm{I}^{\mathrm{f}}$ \\
\hline Median & 54.5 & 55.0 & 64.0 & 62.0 & 0.1298 & 48.5 & 54.0 & $<0.001^{8}$ \\
\hline $\begin{array}{l}\text { Age group } \\
\text { (years), n (\%) }\end{array}$ & & & & & $0.142^{\mathrm{h}}$ & & & $<0.002^{i}$ \\
\hline $40-49$ & $2,027(32.7)$ & $8(22.2)$ & $2(6.3)$ & II (I5.9) & & $97(56.4)$ & $33(34.7)$ & \\
\hline $50-59$ & $1,978(31.9)$ & $15(4 \mid .6)$ & $10(31.3)$ & $19(27.5)$ & & $47(27.3)$ & $30(31.6)$ & \\
\hline $60-69$ & $1,166(18.8)$ & $4(11.1)$ & $10(31.3)$ & $12(17.4)$ & & $15(8.7)$ & $16(16.8)$ & \\
\hline$\geq 70$ & $1,025(16.5)$ & $9(25.0)$ & $10(31.3)$ & $27(39.1)$ & & $13(7.6)$ & $16(16.8)$ & \\
\hline
\end{tabular}

Notes: ${ }^{2}$ COPD reported to have been clinically diagnosed by a pulmonary specialist. ${ }^{\mathrm{b}}$ Respiratory symptoms that fulfill the epidemiological case definition of COPD and ever-

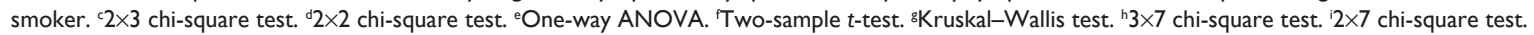
Abbreviations: ANOVA, analysis of variance; SD, standard deviation. 
Table 2 Characteristics of definite and possible COPD subjects by number of comorbidities

\begin{tabular}{|c|c|c|c|c|}
\hline \multirow[t]{2}{*}{ Characteristic } & \multicolumn{3}{|c|}{ Number of comorbidities } & \multirow[t]{2}{*}{ P-value } \\
\hline & None $(n=233)$ & One $(n=119)$ & Two or more $(n=52)$ & \\
\hline Sex, n (\%) & & & & $0.874^{\mathrm{a}}$ \\
\hline Male & I84 (79.0) & $93(78.2)$ & $42(80.8)$ & \\
\hline Female & $49(21.0)$ & $26(21.8)$ & $10(19.2)$ & \\
\hline \multicolumn{5}{|l|}{ Age } \\
\hline Mean \pm SD & $52.6 \pm 11.04$ & $59.6 \pm 12.44$ & $64.5 \pm 10.58$ & $<0.001^{\mathrm{b}}$ \\
\hline Median & 49 & 59 & 62 & $<0.001^{c}$ \\
\hline \multicolumn{5}{|l|}{ CAT score } \\
\hline Mean \pm SD & $|2.5 \pm 7.0|$ & $13.3 \pm 7.00$ & $16.5 \pm 7.63$ & $0.002^{\mathrm{d}}$ \\
\hline Median & 12 & 13 & 15 & $0.005^{c}$ \\
\hline \multicolumn{5}{|l|}{ mMRC score } \\
\hline Mean \pm SD & $0.7 \pm 0.94$ & $0.7 \pm 0.69$ & $1.1 \pm 1.08$ & $0.022^{\mathrm{d}}$ \\
\hline Median & 0 & 1 & 1 & $0.011^{c}$ \\
\hline \multicolumn{5}{|c|}{ Receive treatment, n (\%) } \\
\hline Yes & $39(16.7)$ & $28(23.5)$ & $23(44.2)$ & $<0.001^{\mathrm{e}}$ \\
\hline No & $194(83.3)$ & 91 (76.5) & $29(55.8)$ & \\
\hline \multicolumn{5}{|c|}{ Times admitted to ICU or intubated } \\
\hline Mean & $0.0 \pm 0.00$ & $0.2 \pm 0.45$ & $0.8 \pm 0.84$ & $0.019^{f}$ \\
\hline Median & 0 & 0 & I & $0.030^{c}$ \\
\hline
\end{tabular}

Notes: ${ }^{2} 2 \times 3$ Cochran-Mantel-Haenszel test. ${ }^{\mathrm{b} O n e-w a y ~ A N O V A: ~} \geq 2$ comorbidities, $>$ | comorbidity, and $>0$ comorbidity. ${ }^{\mathrm{C} K r u s k a l-W a l l i s}$ test. ${ }^{\mathrm{d}}$ One-way ANOVA: $\geq 2$ comorbidities, $>0$ comorbidity, $\geq 2$ comorbidities, and $>1$ comorbidity. ${ }^{e} 2 \times 3$ chi-square test. 'One-way ANOVA: $\geq 2$ comorbidities, and $>0$ comorbidity.

Abbreviations: ANOVA, analysis of variance; CAT, COPD Assessment Test; ICU, intensive care unit; mMRC, modified Medical Research Council Breathlessness Scale; SD, standard deviation.

respondents reported being diagnosed with COPD; most had received chest X-radiography $(84.7 \%)$ and pulmonary function testing $(58.4 \%)$, but fewer had a computed tomography scan (39.4\%) and a relatively lower proportion had ever been examined by spirometry. However, more than half of all patients with COPD diagnosed in medical centers $(54.3 \%)$ had computed tomography scans to evaluate pulmonary parenchyma, especially emphysema.

\section{Medical treatments}

Among subjects with definite COPD, fewer than half of ever-smokers $(36.8 \%)$ or never-smokers $(47.8 \%)$ had received medical treatments for their respiratory symptoms and a significantly smaller minority of those with possible COPD had received such treatment (Table 3). There were still lower proportions of subjects currently receiving medications regularly and promptly. For example, few subjects with definite COPD (4.5\%) reported currently taking combined inhaled and oral medications. Compared to never-smokers with definite COPD, ever-smokers with definite or possible COPD reported more frequent emergency department visits, intensive care unit admissions, and hospitalization (Table 3).

Multivariate logistic regression analysis showed that the main risk factors contributing to health care utilization in subjects with definite COPD or possible COPD were higher CAT scores (odds ratio [OR] 1.15, 95\% confidence interval [CI] 1.04-1.26), higher mMRC scores (OR 1.97, 95\% CI 1.11-3.51), and having two or more comorbidities (OR 5.19, 95\% CI 1.05-25.61).

\section{Demographics, symptoms, and health care utilization of ever-smoker versus never-smoker COPD cohorts}

Compared with never-smoking COPD subjects, the COPD cohorts with smoking history had a significant predominance of males and significantly younger average age (Table 4). The mMRC and CAT scores of ever-smokers and never-smokers did not show statistically significant differences in the impact of their respiratory symptoms. A significantly higher proportion of never-smokers than ever-smokers reported receiving regular medical treatment, and ever-smokers had significantly higher rates of health care utilization, especially hospitalization and being intubated.

\section{Discussion}

This large-scale nationwide survey in Taiwan has revealed new insights about the epidemiology, burden, and impact of COPD and its associated comorbidities and risk factors, with important implications for preventive and management strategies. 
Table 3 Treatment and medical utilization among subjects with definite and possible COPD

\begin{tabular}{|c|c|c|c|c|}
\hline \multirow[t]{3}{*}{ Metric } & \multicolumn{3}{|l|}{ COPD cohorts } & \multirow[t]{3}{*}{$P$-value } \\
\hline & \multicolumn{2}{|l|}{ Definite $^{a}$} & \multirow{2}{*}{$\begin{array}{l}\text { Possible }^{b} \\
\text { Ever-smokers } \\
(n=267)\end{array}$} & \\
\hline & $\begin{array}{l}\text { Ever-smoker } \\
(n=68)\end{array}$ & $\begin{array}{l}\text { Never-smoker } \\
(n=69)\end{array}$ & & \\
\hline \multicolumn{5}{|l|}{$\mathrm{mMRC}$} \\
\hline Mean \pm SD & $0.7 \pm 0.91$ & $1.0 \pm 0.90$ & $0.7 \pm 0.90$ & $0.162^{c}$ \\
\hline Median & I & I & 0 & $0.035^{d}$ \\
\hline \multicolumn{5}{|l|}{ CAT } \\
\hline Mean \pm SD & $14.6 \pm 8.23$ & $14.6 \pm 8.46$ & $12.6 \pm 6.49$ & $0.037^{\mathrm{e}}$ \\
\hline Median & 13 & 15 & 12 & $0.099^{f}$ \\
\hline \multicolumn{5}{|c|}{ Number of comorbidities } \\
\hline Mean \pm SD & $0.6 \pm 0.82$ & $0.8 \pm 0.91$ & $0.5 \pm 0.67$ & $0.010^{\mathrm{g}}$ \\
\hline Median & 0 & 1 & 0 & $0.046^{d}$ \\
\hline \multicolumn{5}{|c|}{ Receive treatment, n (\%) } \\
\hline Yes & $25(36.8)$ & $33(47.8)$ & $32(12.0)$ & $<0.00 \mathrm{I}^{\mathrm{h}}$ \\
\hline No & $43(63.2)$ & $36(52.2)$ & $235(88.0)$ & \\
\hline \multicolumn{5}{|c|}{ Times visited ER } \\
\hline Mean \pm SD & $2.9 \pm 8.25$ & $0.2 \pm 0.44$ & $1.1 \pm 1.26$ & $0.416^{c}$ \\
\hline Median & 0 & 0 & I & $0.169^{f}$ \\
\hline \multicolumn{5}{|c|}{ Times hospitalized } \\
\hline Mean \pm SD & $0.6 \pm 1.12$ & $0.0 \pm 0.00$ & $1.6 \pm 2.93$ & $0.139^{c}$ \\
\hline Median & 0 & 0 & I & $0.023^{i}$ \\
\hline \multicolumn{5}{|c|}{ Times admitted to ICU or intubated } \\
\hline Mean \pm SD & $0.2 \pm 0.38$ & $0.0 \pm 0.00$ & $0.3 \pm 0.59$ & $0.368^{c}$ \\
\hline Median & 0 & 0 & 0 & $0.373^{f}$ \\
\hline
\end{tabular}

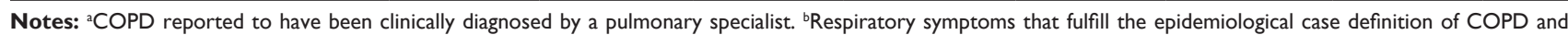
ever-smoker. 'One-way ANOVA. 'Kruskal-Wallis test: COPD never-smoker > possible COPD. 'One-way ANOVA: COPD ever-smoker > possible COPD; COPD neversmoker > possible COPD. 'Kruskal-Wallis test. ${ }^{8}$ One-way ANOVA: COPD never-smoker $>$ possible COPD. ${ }^{\mathrm{h}} 2 \times 3$ chi-square test. ${ }^{\mathrm{K}} \mathrm{Kruskal}$-Wallis test: possible COPD $>$ COPD never-smoker.

Abbreviations: ANOVA, analysis of variance; CAT, COPD Assessment Test; ER, emergency room; ICU, intensive care unit; mMRC, modified Medical Research Council Breathlessness Scale; SD, standard deviation.

\section{Study strengths and limitations}

The methodology we used had both strengths and limitations and differs from that used in previous epidemiological studies; this may provide a fresh perspective on COPD in the general population. Telephone sampling has several merits. It permits random nonclustered sampling of units, eliminates interviewer control over sample selection, and provides anonymity for the respondent, thereby eliminating biases introduced by surveys of subjects referred to a specialist or for pulmonary function testing. In particular, results with such subjects are probably skewed toward increased severity. Although it is possible to solicit information about persistent airway symptoms over the telephone, as in our survey, this relies on respondents' self-reported recall of prior symptoms or diagnosis, which is less accurate than clinical assessment of the presence or absence of airflow limitation. For this reason, our survey is likely to be biased toward underestimating the prevalence of COPD. However, it is also possible that some cases of asthma or cardiovascular disease may have been included in the COPD cohorts, which would lead the prevalence of COPD to be overestimated.
A further limitation was the response rate below the level of $60 \%$ that is generally deemed necessary to avoid bias. ${ }^{13}$ Nevertheless, conducting a telephone survey has the advantages of providing information that is closer to "real life" with full population coverage that enabled us to systematically identify a national probability sample of subjects with a likely diagnosis of COPD. Although we used quotas based on national demographic data to ensure a representative population sample, a telephone-based survey may be subject to a selection bias toward urban populations. It is also likely that elderly subjects residing in long-term care facilities were undersampled. Our survey was not designed to assess compliance with current guidelines, which recommended diagnostic assessment of COPD by measuring lung function and intensive use of bronchodilator agents to improve lung function and symptoms. ${ }^{14}$

\section{COPD prevalence}

The different methods used to estimate disease prevalence expert opinion, patient-reported diagnosis, symptom based, or spirometry based - influence the results. We estimated 
Table 4 COPD cohorts demographics and respiratory symptoms severity by smoking status

\begin{tabular}{|c|c|c|c|}
\hline \multirow[t]{3}{*}{ Metric } & \multirow{3}{*}{$\begin{array}{l}\text { Ever-smokers } \\
\text { Definite }^{a} \text { and possible } \\
\text { COPD }(n=335)\end{array}$} & \multirow{3}{*}{$\frac{\text { Never-smokers }}{\text { Definite COPD }(n=69)}$} & \multirow[t]{3}{*}{$P$-value } \\
\hline & & & \\
\hline & & & \\
\hline Sex, n (\%) & & & $<0.001^{c}$ \\
\hline Male & $297(88.7)$ & $22(31.9)$ & \\
\hline Female & $38(11.3)$ & $47(68.1)$ & \\
\hline \multicolumn{4}{|l|}{ Age } \\
\hline Mean \pm SD & $54.7 \pm|1.7|$ & $63.4 \pm 12.22$ & $<0.00 \mathrm{I}^{\mathrm{d}}$ \\
\hline Median & 52 & 62 & $<0.001^{\mathrm{e}}$ \\
\hline \multicolumn{4}{|l|}{$\mathrm{mMRC}$} \\
\hline Mean \pm SD & $0.7 \pm 0.90$ & $1.0 \pm 0.90$ & $0.067^{d}$ \\
\hline Median & 0 & I & $0.015^{\mathrm{e}}$ \\
\hline \multicolumn{4}{|l|}{ CAT } \\
\hline Mean \pm SD & $12.9 \pm 6.89$ & $14.6 \pm 8.46$ & $0.156^{\mathrm{d}}$ \\
\hline Median & 12 & 15 & $0.140^{\mathrm{e}}$ \\
\hline \multicolumn{4}{|l|}{ Number of comorbidities } \\
\hline Mean \pm SD & $0.5 \pm 0.71$ & $0.8 \pm 0.91$ & $0.027^{d}$ \\
\hline Median & 0 & 1 & $0.034^{e}$ \\
\hline Receive treatment, $\mathrm{n}(\%)$ & & & $0.369^{c}$ \\
\hline Yes & $57(17.0)$ & $33(47.8)$ & $<0.001^{c}$ \\
\hline No & $278(83.0)$ & $36(52.2)$ & \\
\hline \multicolumn{4}{|l|}{ Times visited ER } \\
\hline Mean \pm SD & $1.9 \pm 5.55$ & $0.2 \pm 0.44$ & $0.367^{d}$ \\
\hline Median & 0 & 0 & $0.152^{\mathrm{e}}$ \\
\hline \multicolumn{4}{|l|}{ Times hospitalized } \\
\hline Mean \pm SD & $1.2 \pm 2.27$ & $0.0 \pm 0.00$ & $0.014^{\mathrm{d}}$ \\
\hline Median & 0 & 0 & $0.047^{e}$ \\
\hline \multicolumn{4}{|c|}{ Times admitted to ICU or intubated } \\
\hline Mean \pm SD & $0.2 \pm 0.50$ & $0.0 \pm 0.00$ & $0.03 \mathrm{I}^{\mathrm{d}}$ \\
\hline Median & 0 & 0 & $0.433^{\mathrm{e}}$ \\
\hline
\end{tabular}

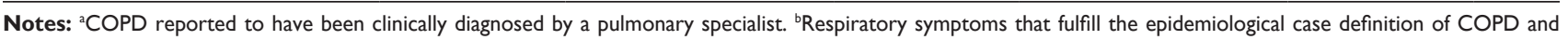
ever-smoker. ${ }^{2} 2 \times 2$ chi-square test. ${ }^{\top}$ Two-sample $T$-test. ${ }^{~} W$ ilcoxon rank sum test.

Abbreviations: ANOVA, analysis of variance; CAT, COPD Assessment Test; ER, emergency room; ICU, intensive care unit; mMRC, modified Medical Research Council Breathlessness Scale; SD, standard deviation.

the national prevalence of COPD in adults aged 40 years and older to be $6.1 \%$. This is higher than a previously reported figure of $\sim 2.5 \%$ based on national health insurance claims. ${ }^{7}$ Given that our survey may have been biased toward underestimating the prevalence of COPD, it seems very likely that this discrepancy reflects substantial underdiagnosis of COPD among the general population. From age-specific prevalence data (Table 1), we may infer that most cases of COPD in Taiwan are not definitively diagnosed until after age 50, even among current or former smokers.

The prevalence of COPD has been studied in many countries, with wide variations depending on the diagnostic criteria used and the age group analyzed, from only $0.2 \%$ in Japan to $37.0 \%$ in the USA. ${ }^{15}$ Crude COPD prevalence rates reported by a study in five Latin American cities ranged from $7.8 \%$ in Mexico City to $19.7 \%$ in Montevideo. ${ }^{16}$ In Kentucky, USA, ${ }^{17} 19.6 \%$ of subjects met criteria for Global initiative for chronic Obstructive Lung Disease stage 1 or higher COPD, and the rate is $16.2 \%$ in Uppsala, Sweden. ${ }^{18}$ In the People's Republic of China, COPD is one of the most common chronic diseases in the population older than 40 years of age, with a prevalence of $8.2 \% .{ }^{6}$ Comparatively lower prevalence of $6.1 \%$ in Taiwan may reflect lower rates of tobacco smoking. Another recent study of the impact of COPD in the Asia-Pacific region - the Epidemiology and Impact of COPD (EPIC) Asia population-based survey ${ }^{19}$ used a similar methodology to our study, with face-to-face or fixed-line telephone interviews. The estimated prevalence of COPD in Taiwan was 9.5\%. However, the EPIC study involved only 207 subjects in Taiwan, whereas our survey with 6,600 participants, the much larger sample size, would be expected to yield more accurate epidemiological data. Furthermore, our survey included questions from the CAT and mMRC questionnaires to investigate the risk factors contributing to health care utilization in patients with COPD, which the EPIC survey did not. 


\section{COPD symptoms severity and treatment}

Chronic respiratory symptoms were common among subjects with diagnosed COPD as well as those with possible COPD. Despite the majority of subjects surveyed having received their care primarily from general practitioners and one in five reporting never having undergone any lung function testing, their symptom severity, as indicated by breathlessness and medical utilization, was still high. However, only a low proportion of patients with diagnosed COPD reported receiving prescribed inhalers regularly. In addition, health care utilization was frequent in patients with COPD. Collectively, these results indicate that COPD is not only relatively prevalent in Taiwan but also has a major impact on quality of life and is very probably underdiagnosed and inappropriately treated.

\section{COPD comorbidities and risk factors}

Our results affirm that extrapulmonary manifestations and comorbidities are important issues in COPD. Similar to other studies that have shown cardiovascular diseases to be frequent in patients with COPD,,$^{20,21}$ hypertension or other cardiovascular diseases were the most common comorbidities in our COPD cohorts. Comorbid conditions are associated with significantly worsening health-related quality of life as the number of comorbid diseases increases..$^{22,23}$ Likewise, in our study, CAT scores were higher in subjects with two or more comorbidities than in those with one or no comorbidity. Moreover, having more comorbidities was an important independent risk factor for frequent acute exacerbations and hospitalization. The large proportions of subjects who had not undergone diagnostic testing and had not received training in inhaler use suggest that the key recommendations of current guidelines are far from being uniformly implemented in Taiwan. For these reasons, there is an urgent need to raise awareness of the importance of diagnosing comorbidities and extrapulmonary manifestations early in patients with evident respiratory symptoms and impaired quality of life and of treating them promptly and appropriately in order to spare medical resource ultilization.

\section{Conclusion}

Based on a random nationwide telephone survey, the prevalence of COPD in the adult population of Taiwan is $6.1 \%$. Subjects with COPD, especially those with several comorbidities have poor health, are underdiagnosed and undertreated, and have high levels of medical resource utilization. Given that COPD is preventable and treatable, our findings reinforce the urgency of increasing awareness of COPD, as outlined in the objectives of the Global initiative for chronic Obstructive Lung Disease initiative. ${ }^{14}$ The presence of respiratory symptoms and risk factors for COPD should increase the index of suspicion for disease diagnosis. Our survey highlights the need for enhanced screening efforts in high-risk populations such as smokers, subjects with chronic airway symptoms, and comorbidities, in order to provide timely and appropriate management.

\section{Acknowledgments}

This study was supported financially by Takeda Pharmaceuticals Taiwan, Ltd. However, the sponsor had no role in the study design, data collection or analysis, or the decision to publish. Takeda staff reviewed early drafts of the manuscript, but the authors were independent in deciding whether to incorporate feedback and approving the final revised version. Dr David Neil (PhD), of Content Ed Net Taiwan Limited, provided writing and editorial assistance, which was funded by Takeda.

\section{Disclosure}

The authors report no conflicts of interest in this work.

\section{References}

1. Chen JC, Mannino DM. Worldwide epidemiology of chronic obstructive pulmonary disease. Curr Opin Pulm Med. 1999;5:93-99.

2. Murray CJ, Lopez AD. Alternative projections of mortality and disability by cause 1990-2020: global burden of disease study. Lancet. 1997;349:1498-1504

3. Halbert RJ, Natoli JL, Gano A, Badamgarav E, Buist AS, Mannino DM. Global burden of COPD: systematic review and meta-analysis. Eur Respir J. 2006;28:523-532.

4. Mathers CD, Loncar D. Projections of global mortality and burden of disease from 2002 to 2030. PLoS Med. 2006;3:e442.

5. Ko FW, Hui DS, Lai CK. Worldwide burden of COPD in high- and low-income countries. Part III. Asia-Pacific studies. Int J Tuberc Lung Dis. 2008;12:713-717.

6. Zhong N, Wang C, Yao W, et al. Prevalence of chronic obstructive pulmonary disease in China: a large, population-based survey. Am J Respir Crit Care Med. 2007;176:753-760.

7. Wang YC, Lin JM, Li CY, Lee LT, Guo YL, Sung FC. Prevalence and risks of chronic airway obstruction: a population cohort study in Taiwan. Chest. 2007;131:705-710.

8. Kuo LC, Yang PC, Kuo SH. Trends in the mortality of chronic obstructive pulmonary disease in Taiwan, 1981-2002. J Formos Med Assoc. 2005; 104:89-93.

9. Jensen HH, Godtfredsen NS, Lange P, Vestbo JL. Potential misclassification of causes of death from COPD. Eur Respir J. 2006;28:781-785.

10. Salvi SS, Barnes PJ. Chronic obstructive pulmonary disease in nonsmokers. Lancet. 2009;374:733-743.

11. Stenton C. The MRC breathlessness scale. Occup Med (Lond). 2008;58: 226-227.

12. Jones PW, Harding G, Berry P, Wiklund I, Chen WH, Kline Leidy N. Development and first validation of the COPD assessment test. Eur Respir J. 2009;34:648-654.

13. Groves RM. Nonresponse rates and nonresponse bias in household surveys. Public Opin Q. 2006;70:646-675. 
14. Global Initiative for Chronic Obstructive Lung Disease (GOLD). Global Strategy for the Diagnosis, Management, and Prevention of Chronic Obstructive Pulmonary Disease. [Guidelines on the internet]. Updated February 2013 [cited June 1, 2015]. Available from: www.goldcopd. org/uploads/users/files/GOLD_Report_2013_Feb20.pdf. Accessed June 1,2015

15. Rycroft CE, Heyes A, Lanza L, Becker K. Epidemiology of chronic obstructive pulmonary disease: a literature review. Int J Chron Obstruct Pulmon Dis. 2012;7:457-494.

16. Menezes AM, Perez-Padilla R, Jardim JR, et al; Platino Team. Chronic obstructive pulmonary disease in five Latin American cities (the PLATINO study): a prevalence study. Lancet. 2005;366:1875-1881.

17. Methvin JN, Mannino DM, Casey BR. COPD prevalence in southeastern Kentucky: the burden of lung disease study. Chest. 2009;135: 102-107.

18. Danieisson P, Ólafsdóttir IS, Benediktsdóttir B, Gíslason T, Janson C. The prevalence of chronic obstructive pulmonary disease in Uppsala, Sweden-the Burden of obstructive lung disease (BOLD) study: crosssectional population-based study. Clin Respir J. 2012;6:120-127.
19. Lim S, Lam DC, Muttalif AR, et al. Impact of chronic obstructive pulmonary disease (COPD) in the Asia-Pacific region: the EPIC Asia population-based survey. Asia Pac Fam Med. 2015;14:4.

20. Bellocchia M, Masoero M, Ciuffreda A, et al. Predictors of cardiovascular disease in asthma and chronic obstructive pulmonary disease. Multidiscip Respir Med. 2013;8:58.

21. de Miguel Díez J, Chancafe Morgan J, Jiménez García R. The association between COPD and heart failure risk: a review. Int J Chron Obstruct Pulmon Dis. 2013;8:305-312.

22. López Varela MV, Montes de Oca M, Halbert R, et al; Platino Team. Comorbidities and health status in individuals with and without COPD in five Latin American cities: the PLATINO study. Arch Bronconeumol. 2013;49:468-474.

23. Jones PW, Brusselle G, Dal Negro RW, et al. Health-related quality of life in patients by COPD severity within primary care in Europe. Respir Med. 2011;105:57-66.
International Journal of COPD

\section{Publish your work in this journal}

The International Journal of COPD is an international, peer-reviewed journal of therapeutics and pharmacology focusing on concise rapid reporting of clinical studies and reviews in COPD. Special focus is given to the pathophysiological processes underlying the disease, intervention programs, patient focused education, and self management protocols.

\section{Dovepress}

This journal is indexed on PubMed Central, MedLine and CAS. The manuscript management system is completely online and includes a very quick and fair peer-review system, which is all easy to use. Visit http://www.dovepress.com/testimonials.php to read real quotes from published authors.

Submit your manuscript here: http://www.dovepress.com/international-journal-of-chronic-obstructive-pulmonary-disease-journal 